\title{
Telework as a Means of Organizational Identity Change: Investigating Japanese Collectivist Culture in an ICT Company
}

\author{
Akira Kimata \\ Meiji University \\ kimata@kt.rim.or.jp
}

\author{
Masayasu Takahashi \\ Meiji University \\ taka-masa@ttv.ne.jp
}

\begin{abstract}
Due to the COVID-19 pandemic, numerous companies have implemented telework to balance business continuity with employees' safety. However, telework was not a widespread phenomenon in Japan until recently. Why is a geographically decentralized workstyle not as widespread in Japan as in other nations? In a previous study, based on collected samples from 529 Japanese companies, we used statistical analyses and clarified that the communication style aligned with Japanese collectivism seriously hinders telework. The present study used qualitative analysis to investigate how the communication style associated with Japanese collectivist culture hinders the introduction of telework. Finally, we concluded that if a non-Western cultural company introduces telework, it should remove the negative aspects of the communication style associated with collectivist culture to bring about organizational change that leads to a new organizational identity.
\end{abstract}

\section{Introduction}

In response to the novel coronavirus disease (COVID-19) spread, many companies have implemented telework on a global scale. Telework is a geographically decentralized workstyle [1][2]. Nilles et al. defined it as the "partial or complete replacement of commuting by communications technology that can include computers" [3]. Originally, telework was viewed favorably as a way of increasing white-collar productivity and improving work/life balance $[4,5]$. It has also received attention from researchers as one means of continuing work during a pandemic. Specifically, home-based telework has been implemented by companies attempting to balance

\footnotetext{
${ }^{1}$ Source: MHLW, https://www.mhlw.go.jp/stf/newpage_11109.html

${ }^{2}$ Source: Nikkei Business, https://business.nikkei.com/atcl/seminar/ 19/00030/052100102/

${ }^{3}$ The survey was conducted on workers in the USA, the UK, Germany, Italy, Sweden, South Korea, China, and Japan in July
}

business continuity with employees' safety, during COVID-19 [6, 7].

However, telework was historically not a widespread practice in Japan. In the spring of 2020, the Ministry of Health, Labor, and Welfare (MHLW) and LINE Corporation conducted three separate research on Japanese work styles related to COVID-19. They found that the implementation rate of home-based telework for office workers (office work, planning, development, etc.) was $13.99 \%$ nationwide, on average, in the first survey, March $31^{\text {st }}$ to April $1^{\text {st }}(\mathrm{N}=6,088,488)$. In the second survey, April $5^{\text {th }}$ to April $6^{\text {th }}$, the implementation rate was $16.2 \%$ on average $(\mathrm{N}=6,531,337){ }^{1}$. In the third survey, April $12^{\text {th }}$ to April $13^{\text {th }}$, the introduction rate increased further. During the governmental declaration of the COVID-19 emergency, the implementation rate averaged $26.83 \%$ nationally for office work-centered employees $(\mathrm{N}=6,283,871)$. In Tokyo, the rate was the highest at $51.88 \%$. The lowest rate was $3.27 \%$ in the region of Shimane Prefecture, far west from Tokyo. The Japanese government aimed for a minimum $70 \%$ homebased telework implementation rate; however, the realization was well below the goal. Furthermore, many Japanese companies stopped telework after the governmental declaration of the COVID-19 emergency was lifted ${ }^{2}$.

Additionally, according to the research on the telework implementation rate, comparing eight nations $[8]^{3}$, due to the spread of COVID-19, the introduction rate in Japan was $31 \%$, the lowest among the eight nations. The introduction rate of China was the highest at $75 \%$; the USA and the UK were $61 \%$ and $55 \%$, respectively ${ }^{4}$. This, thus, begs the question: why is the geographically decentralized workstyle not as widespread in Japan as in other nations?

In a previous survey [9], which collected samples of 529 Japanese companies, we used statistical analyses

2020. The survey collected 2,060 samples from city dwellers of each country.

${ }^{4}$ We presume that the high introduction rate of China mainly derives from the national institution by the Chinese Communist Party, but the issue is beyond the discussion of this paper. 
and identified that a serious impediment to the introduction of telework was the communication style aligned with Japanese collectivism ${ }^{5}$. Based on this finding, the present study investigates how the communication style of Japanese collectivist culture hinders the introduction of telework, through a qualitative analysis of an ICT company. Finally, we propose a conclusion, that if telework is one of the methods of acquiring new competitiveness, then the non-Western culture companies might need to rid themselves of negative aspects of collectivist culture, represented by "Sontaku" or "Nemawashi"," and experience organizational change by incorporating a new organizational identity.

\section{Framework}

\subsection{Collectivist culture as an impediment}

In a study of national culture, Hofstede [10, 11] quantitatively conceptualized mainly four indexes as the multidimensional variables. This study focuses on two of them, individualism index and power distance index, which tend to be negatively correlated. According to Hofstede [11, p. 54], large power distance countries are likely to be more collectivist and small power distance countries to be more individualist. The former tends to prevail in less developed or Eastern countries such as Japan, South Korea, and Taiwan, and the latter in more developed or Western countries. Therefore, we assume that Japanese collectivist culture includes elements of large power distance. Citing his research, Ramamoorthy and Carroll [12] investigated the traits of collectivism through research results, which supported the following hypothesis: collectivism encourages collective interests and cooperative behaviors, and is positively associated with such behaviors exhibited by organizational members, regarding its tasks [12, p. 573]. Their finding asserts the positive elements of collectivism, which are also supported by Huff and Kelley [1], who insisted that Japanese collectivism allows for trust. In other words, Japan is often used as a collective cultural model for fostering trust and cooperation [1, p. 82]. Further, they emphasized that the Japanese concept of "Wa" (Japanese term designating harmony) involves sharing, cooperation, warmth, and fellowship, leading to trust in a work context. "Wa" positively affects the organizational outcome.

However, Japanese collectivism has not only positive effects but also negative effects [1, 13, 14, 15].

\footnotetext{
5 The population of this survey was a total of 1,873 Japanese companies who were surveyed by e-mail in the autumn of 2002. There were 534 responses (529 of which were valid), and the response rate was $28.24 \%$.
}

Yamagishi $[13,14]$ stated that Japanese collectivism has interfered with developing the original meaning of trust. Moreover, it has maintained a relationship of "Anshin" (Japanese term designating relief) among Japanese employees. He demonstrated that the original meaning of trust is based on an expectation of others' human nature. He also insisted that this behavioral characteristic is mainly developed in the individualistic culture of Western countries. However, Japanese collectivism developed the concept of "Anshin," based on the expectation of mutual loss and gain calculation. Yamagishi [13, 14] examined Japan-USA research findings to specifically conclude that the relationship of

"Anshin" is the nature of Japanese collectivism, which does not encourage prioritizing group interests over personal ones; instead, it encourages a social mechanism of mutual supervision and regulation to prevent people from acting against group interests during face-to-face interactions [14, p. 45].

Borrowing the idea of "Anshin," we can focus on how mutual supervision and regulation are performed, and what the key factor of this interaction is. We examine these traits below. This study cites the work of Markus \& Kitayama [16], which demonstrates the differences in the concept of "self" between Western and Asian cultures (Figure 1).

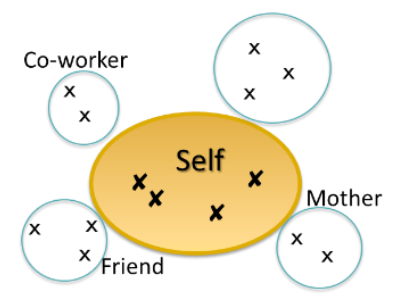

Independent view of self in Western culture

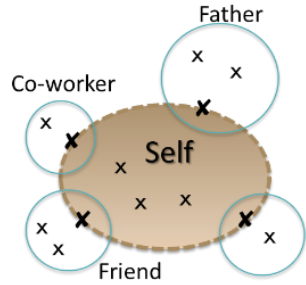

Interdependent view of self in Asian culture
Source: Markus and Kitayama [16, p. 226].

\section{Figure 1. Difference between the two types of self in Western and Asian cultures}

According to Markus and Kitayama [16], the difference in interactions within Western and Asian cultures derives from a difference in the definition of self. There are two types of self: the first is the independent view of the self, based on a belief in the wholeness or fullness of each person's internal attributes. The second is the interdependent view of the self, which positions a person as more connected and less differentiated. In the independent view, the bold Xs

\footnotetext{
6 The term "Sontaku" expresses tacit understanding. Further details will be shown later in this paper. The term of "Nemawashi" generally means laying the groundwork by manipulating the situation behind the scenes.
} 
represent the various aspects of the self, for example, individual desire or preference, and are called selfschema in a psychological context. In the interdependent view, others participate actively in the definition of the subject of the self. The bold Xs are organized through what the subject perceives to be thought and felt by others. We posit that Japanese collectivist culture relates to self in the latter form and derives from sensitivity to the relationship with others.

In the previous survey [9], we concluded that "inhouse communication discord" ${ }^{7}$ " was the most significant barrier when it came to adopting telework. Here, we presume that the following is in the background of the previous result: Face-to-face interaction is a great need in the high-context culture of the Japanese workplace, to incorporate the self of the others onto the person's own.

According to Hall [17, p. 91], "high-context communication is one in which most of the information is either in the physical context or internalized in the person, while very little is in the corded, explicit, transmitted part of the message." Thus, the traits of high-context communication mainly consist of indirect, implicit messages. Further, Hall [17, p. 111] claimed that "high-context messages are placed at one end and low-context messages at the other end of a continuum." In the high-context-low-context continuum, the Japanese and Chinese cultures were placed in the former, while the American and German cultures were put in the latter. Based on the Hall's context model, we assume that "meaning, for high-context communicators, is derived less from the information conveyed and more from information preprogrammed within the relationship" and that "context [is] as the shared understanding and tacit common ground that are taken for granted by communicators" [18, p. 569].

As a result, face-to-face interaction in the workplace strengthens mutual supervision and regulation. This subsequently causes a condition in which organizational members come to a deadlock, restraining each other from engaging in negative behavior. We hypothesize that face-to-face interaction is difficult to replace online interaction; therefore, "in-house communication discord" is the most significant barrier to adopting telework. From these, the first research question in the qualitative analysis of this study is: "How does an organizational member organize themself through others in a highcontext culture, by face-to-face interaction?"

If there is a need for an organization to change its style of interaction, the organization might change its culture as symbolic modes [19], as discussed in the subsequent section.

\footnotetext{
${ }^{7}$ In the traditional research of telework [15], the significance of faceto-face interaction in Japanese culture was emphasized by a survey.
}

\subsection{Organizational identity change}

From the perspective of organizational symbolism, which gives the social world much less concrete status, organizations are viewed as having a culture and as containing patterns of symbolic discourse. Both are maintained through symbolic modes, such as language [20, p. 342]. In this perspective, researchers are concerned with the themes representing a pattern of symbolic discourse and those that specify the links among values, beliefs, and actions. Researchers understand that an organization exists only as a pattern of symbolic relationships and meanings through the processes of human interaction. They pay attention to "how is organization accomplished" and "what does it mean to be organized." [20].

Symbols are a visible part of an organizational culture. They manifest their cognitive component and strengthen and modify organizational culture. According to Dandridge et al. [21], symbols are categorized into three types (Figure 2). Material symbols (based on logos, products, and flags) and action symbols (grounded in ritualistic acts or awards) are purely descriptive, compared to verbal symbols (based on myth or legend). Among these three, action symbols function to maintain symbolic relationships and meanings [21].

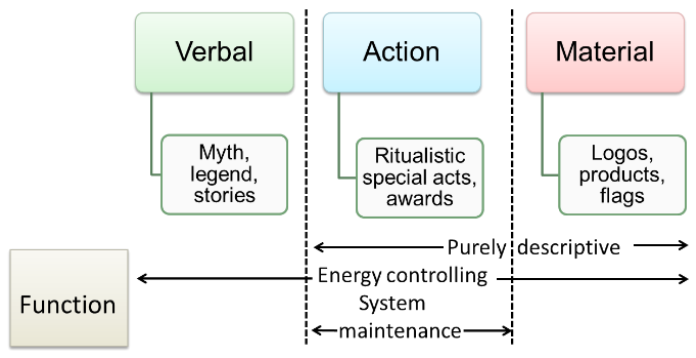

Source: Dandridge, et al. [21, p. 79]

Figure 2. The category of symbols

Conversely, recent organizational cultural studies have investigated the concept of organizational identity. For example, Hatch and Schultz [22] proposed a model of centered organizational identity to demonstrate how it expresses cultural understanding through symbols. Their work is based on four processes: mirroring, reflecting, expressing, and impressing. As their study shows, the term "organizational identity" has opened up a new paradigm in the relationship between organizations and their environment. Moreover, it has attracted researchers' attention in the context of 
organizational studies $[23,24,25]$. We decided to place this concept in the center.

Originally, the term organizational identity was found in Albert and Whetten [26] as a definition of "an organization's self-definition." This demonstrates the need for firms to ask themselves, "Who are we?" in order to continue or adapt their business. This concept consists of three dimensions [26]. First, "central character," which is the essential feature being declared. Second, "distinctiveness," which is the uniqueness in comparison to others. Third, "temporal continuity," which is the portion that does not change, regardless of the passage of time. We mainly focus on "central character" and "distinctiveness" in this study. Among previous studies, from empirical research on multinational manufacturing companies of EU, Ravasi and Schultz [27] demonstrated that organizational identity changes as a twin dynamic process against external threats. This is shown as the "sensegiving" and "sensemaking" processes. The former is based mainly on the social actor perspective. It shows as an identity claim being organizational self-definitions, and then, is mainly proposed by leaders. The latter is based on a social constructionist perspective and shows shared understanding [27].

Through the positivist approach, organizational identity refers to individual members' "perceived organizational identity" [28, p. 189]. Besides, according to Erikson [29], group identity as a group's basic way of organizing experiences is transmitted to individual bodily experiences and to "the beginnings of the ego." The ego refers to a conscious part of the self [30] of an individual. To summarize the discussions, in line with the two abovementioned types of self, the identity of the organizational level is not only perceived and created by the members' self but also embedded within that self. We presume that the linkages of self (individual level) and identity (organizational level) interact with each other.

Here, we decided to employ the above frameworks. We used them to examine the organizational identity change by the introduction of telework. At the same time, we focus on three types of symbol interaction from both sides of sensegiving and sensemaking. The framework of this study is represented in Figure 3.

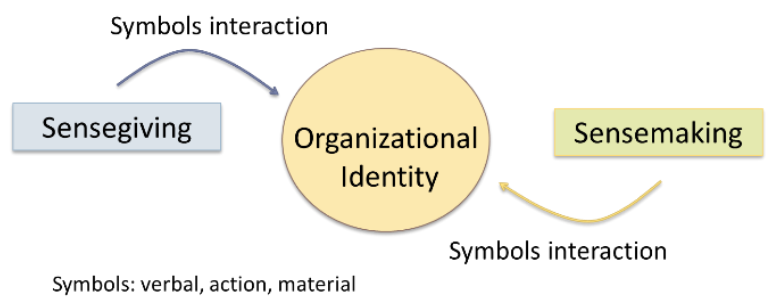

Figure 3. Framework of the study
Simultaneously, the second and third research questions are "Is there any change in the organization through the introduction of telework?" and "Is there an emergence of a new organizational identity?"

As stated above, we posed three research questions. Through the abovementioned RQ1, this study tries to define the traits of communication style associated with Japanese collectivist culture, which might be an impediment to the introduction of telework. Subsequently, through the RQ2 and RQ3, this study will clarify how the communication style associated with Japanese collectivist culture is amended (or not) by the introduction of telework, as well as how the amendment affects (or does not affect) organizational identity.

\section{Methodology and outline}

\subsection{The detail of qualitative method}

In this study, we employed qualitative analysis. Interview methods are roughly divided into directive and non-directive methods, and this study used the latter. Using a semi-structured interview method, we freely exchanged opinions with interviewees, but clarified some significant questions in advance. However, the non-directive method (including the semi-structured method) has some disadvantages. For instance, the interviewed results tend to follow a stereotype, such as of gender, age, and race, thereby affecting the interviewer's skills.

To ensure the reliability of the methods and the validity of the results, Yin [31] emphasized the importance of: (a) maintaining the chain of evidence, (b) creating a case study database, and (c) using multiple sources of evidence. This study was conducted based on these three principles to avoid any possible detriments caused by the semi-structured interview method. For example, we created an interview database and expressly confirmed the facts with every subject via email to secure reliability in the chain of evidence.

Further, while examining interview results, we employed discourse analysis. According to Burr [32], discourse refers to a set of meanings, metaphors, representations, images, stories, and statements, that in some way produce a particular version of events. The method of discourse analysis is based on social constructionism and focuses on the internal psychic structures and processes of attitudes and personality traits of individuals [32, p. 159]. Subsequently, this causes a particular picture to be painted of an event. The process of analysis consists of the following: 1) reading the pieces quite slowly and thoroughly; 2) searching for recurrent themes, coherent sets of phrases in similar ways, and words loaded with meaning; 3) underlining 
and listing the words; and 4) identifying the construct by the story of the event [32, p. 168]. In addition, we identified the link between each discourse and symbol type in line with our framework above. We then marshaled them into the categories of sensegiving and sensemaking.

In the selection of surveyed companies in this study, we searched for and selected samples that adopted home-based telework. We started with ten representative companies, that were awarded prizes by public institutions or were introduced in mass media. These extracted samples ${ }^{8}$ were examined during our pre-interview, regarding the operational condition of their telework. Finally, we decided to pick a sample of a Japanese ICT company called DUNKSOFT Corporation (Tokyo, Japan) as a unique sample from the pre-interviewed companies. The company was transformed from having long work hours and an obligation to work to encouraging a work-life balance and allowing employees to work freely from anywhere through telework. As a result, DUNKSOFT Corporation received 14 awards from the Japanese government and received attention from mass media. We conducted semi-structured interviews of the company's president and staff three times ${ }^{9}$ using the above method and research questions.

\subsection{Outline of the sample}

DUNKSOFT mainly engages in designing websites and developing computer systems. The company was founded in 1983 and as of April 2019, 22 persons were employed (Table 1).

The company is divided into three sections: 1) the web team, in charge of building and updating the homepages of major financial institutions; 2) the system development team, taking on software and system development for work management; 3) the planning team, a relatively new section that provides consulting services of paperless work or regional revival by telework. DUNKSOFT's history can be divided into three stages (Table 2).

In the beginning, the company was founded with the name "Dual System," and their goal was to manufacture an industrial robot. Later, the founding president died. Mr. K. H., the current president, took over the position. In the late 1990s, the company took on a name of a game software that they had designed: "DUNKSOFT." During the third stage from 2003 to 2019, which is considered a landmark stage, the president became

\footnotetext{
${ }^{8}$ These firms included small, medium-sized, and large enterprises and were diverse in their business description, i.e., pharmaceutical, education, consumer electronics, ICT software, and building ICT infrastructure.
}

concerned about the company's future, which made him believe that the small company needed to continue to grow. We focus our attention on this stage.

Table 1. Main profile of the sample

\begin{tabular}{|l|l|}
\hline \multicolumn{2}{|l|}{ DUNKSOFT Corporation (Tokyo, Japan) } \\
\hline $\begin{array}{l}\text { Business } \\
\text { Description }\end{array}$ & $\begin{array}{l}\text { Designing websites and building } \\
\text { homepages, developing computer systems, } \\
\text { improving business efficiency in ICT }\end{array}$ \\
\hline Foundation & 1983 \\
\hline Capital & 10 million yen (April 2019) \\
\hline Employees & 22 (April 2019) \\
\hline Net sales & $\begin{array}{l}\text { 260 million yen (for the year ended June } \\
2017)\end{array}$ \\
\hline Award & $\begin{array}{l}\text { Received 14 awards (promotion of work- } \\
\text { life balance by Ministry of Health, Labor } \\
\text { and Welfare, etc.) }\end{array}$ \\
\hline
\end{tabular}

Table 2. Outline of the DUNKSOFT's history

\begin{tabular}{|l|l|}
\hline $\begin{array}{l}\text { Generation } \\
(1983-96)\end{array}$ & $\begin{array}{l}\text { The company's name was Dual System. It } \\
\text { had the goal of manufacturing industrial } \\
\text { robots. The founding president died in } \\
\text { 1986, and the current president, Mr. K. H., } \\
\text { succeeded to that position. }\end{array}$ \\
\hline $\begin{array}{l}\text { Consistency } \\
(1997-02)\end{array}$ & $\begin{array}{l}\text { The business domain has been changed to } \\
\text { software and system development. The } \\
\text { software game "DUNKSOFT," that the } \\
\text { company developed was adopted as the } \\
\text { new company name. }\end{array}$ \\
\hline $\begin{array}{l}\text { Landmark } \\
\text { change }\end{array}$ & $\begin{array}{l}\text { The president of the company joined the } \\
\text { inter-industry exchange and was } \\
\text { concerned about the company's future. He } \\
\text { contemplated what a small and } \\
\text { insignificant company needs to continue } \\
\text { growing. }\end{array}$ \\
\hline
\end{tabular}

Figure 4 shows the recent condition of telework at DUNKSOFT. The head office is in Tokyo, and the company has eight satellite offices, located in, for instance, Hokkaido, Tochigi, and Tokushima.

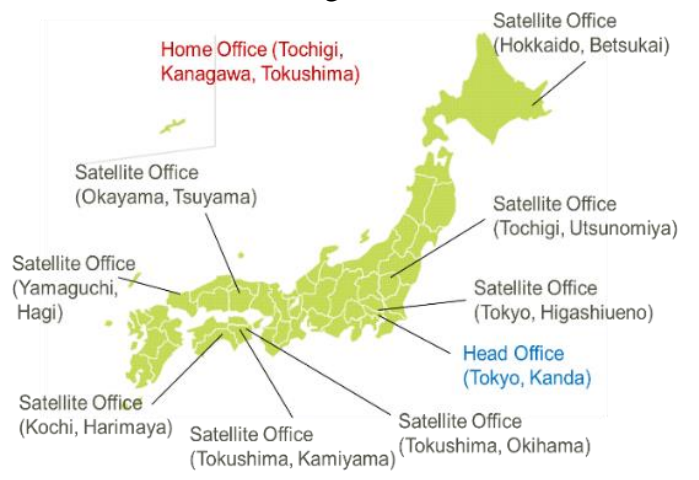

Figure 4. The recent condition of telework

\footnotetext{
${ }^{9}$ Our interviews were conducted on June 2015, January 2018, and April 2019, respectively.
} 
Four employees always work from home. We interviewed five persons (Table 3) and extracted the discourse of three, which is intricately connected to the research questions. The selected persons (Mr. K. H. (63), Ms. K. N. (41) and Mr. Y. T. (39)) were interviewed several times. Their symbolic discourses are presented in the next section.

Table 3. Profile of interviewees ${ }^{10}$

\begin{tabular}{|l|l|}
\hline $\begin{array}{l}\text { Interviewee } \\
(\text { age })\end{array}$ & Career \\
\hline $\begin{array}{l}\text { Mr. K. H } \\
(63)\end{array}$ & $\begin{array}{l}\text { He entered DUNKSOFT during the } \\
\text { startup and became the president of the } \\
\text { company in 1986. }\end{array}$ \\
\hline $\begin{array}{l}\text { Ms. K. N } \\
(41)\end{array}$ & $\begin{array}{l}\text { She joined DUNKSOFT in 2003 and } \\
\text { experienced web team and planning team. } \\
\text { She took childcare leave twice and is } \\
\text { currently working at home. }\end{array}$ \\
\hline $\begin{array}{l}\text { Mr. Y. T } \\
(39)\end{array}$ & $\begin{array}{l}\text { He previously worked as a programmer } \\
\text { for a large software manufacturer for ten } \\
\text { years. After that, he joined DUNKSOFT } \\
\text { in 2012 and is working at a regional } \\
\text { satellite office as the system development } \\
\text { team leader. }\end{array}$ \\
\hline $\begin{array}{l}\text { Mr. M. K } \\
(40)\end{array}$ & $\begin{array}{l}\text { He worked in the same manufacturer as } \\
\text { Takeuchi before. He joined DUNKSOFT } \\
\text { in 2012. }\end{array}$ \\
\hline $\begin{array}{l}\text { Mr. G. T } \\
(34)\end{array}$ & $\begin{array}{l}\text { He was appointed as a new graduate in } \\
\text { 2008 and is currently the leader of the } \\
\text { web team. }\end{array}$ \\
\hline
\end{tabular}

\section{Discourse of the firm}

Here, we examine the discourses of the company employees. At first, Mr. K. H., the president of DUNKSOFT, explained the early years of the landmark stage:

At that time, employees were working until midnight, and the resignation rate was high. The workers were indifferent to the policy of the organization. However, several talented young workers joined us. I was afraid that they [would] leave our company... if I could not provide them with good working conditions.

One of the talented newcomers, Ms. K. N., commented:

I joined DUNKSOFT late in 2003 after changing jobs. The company had a top-down management structure; in those days, every employee was obliged to work through superiors. We proactively had to "read" their demands and intentions without their instructions.

Mr. K. H. illustrated the following image of the new organization:

My image of the new organization was that each member played a "polyvalent" role through

\footnotetext{
${ }^{10}$ Interviewees' ages were recorded during the survey in March 2019.
}

autonomous motivation. However, I could not determine their thoughts and did not know how to motivate them. At the onset, I empowered the recruitment department to ensure the recruitment of talented newcomers. Only then did it steadily become clear what they really expected from DUNKSOFT.

Regarding symbolic events, Ms. K. N. replied:

The way superiors treated us changed gradually, and what we wanted to improve became acceptable. We were truly delighted that our contributions were being valued. The president created a new slogan as a challenge, called "you said it first." After that, members felt equal and interacted informally. I have made many proposals, for example, the placement of IKEA furniture at the office or the increase of maternity leave to three years. A symbolic event still vivid in my memory was a decision approved by the majority, namely creating a new logo for the company. A designer proposed the renewal of the company's logo around 2005. Until then, almost every member was embarrassed about the old logo, but earlier, nobody could openly comment on the executive's design.

Mr. K. H. reflected on the introduction of telework:

It is difficult for a small and insignificant company like DUNKSOFT to hire talented and skilled workers in Tokyo. Thus, in 2011, we started using a teleconference system on a large scale. If there were excellent creators whose family circumstances were such that they had moved to a regional city out of necessity, we created a satellite office there to accommodate them.

As an example of the above case, Mr. Y. T. expressed the following, from the Tokushima satellite office:

In early 2012, I resigned [from] a large Tokushimabased software manufacturer because I refused a transfer to Tokyo. My first child was born at the time, and I reevaluated my work style for my family's sake. I had worked until late at night because the company imposed a heavy work quota on us. However, I thought it was good for me, because I experienced fulfillment in my work.

After that, I searched for a job in Tokushima city and looked at the satellite office experiment of DUNKSOFT. I was really impressed that we could work from anywhere. After joining DUNKSOFT, I realized that self-sacrifice for the sake of a company is bad. My sense of belonging to DUNKSOFT gradually became stronger because all members work together in a geographically dispersed organization.

About the public acknowledgments of the company's achievements, Mr. K. H. said,

We were awarded the first prize for promoting a work-life balance, by Tokyo Prefecture in 2010, which 
deeply surprised us since we did not think our activities were special. After that, DUNKSOFT was awarded more than ten prizes and responded to many interviews through mass media. We realized that our company is exceptional and that the new in-house trials developed into a new business, for instance, outsourcing through telework.

\section{Discussion}

\subsection{Examination of RQ1}

This section examines the above discourses in line with our method and the central research questions. As a reminder, our central research questions are: "How does an organizational member organize themself through others in a high-context culture, by face-to-face interaction?" (RQ1); "Is there any change in the organization through the introduction of telework?" (RQ2); and "Is there an emergence of a new organizational identity?" (RQ3). We sorted the discourses between the themes of the two research questions (RQ1 and RQ2/RQ3) and extracted phrases or words that were recurrent and/or loaded with meaning (Tables 4 and 5). First, we investigated discourses 1-3 regarding RQ1 (Table 4).

\section{Table 4. Discourses regarding RQ1}

RQ1: Organizing self among others in a high-context culture

1) Proactively had to "read" superiors' wishes without instructions (Ms. K. N.)

2) Not catching their real thoughts (Mr. K. H.)

3) Deeply embarrassed by the old logo, but nobody could openly comment on the executive's design (Ms. K. N.)

According to discourses, there are some traits that are specific to high-context cultures. For example, employees "have to proactively read" the intentions and demands of superiors "without their instructions," based on discourse 1 (abbreviated as " $\mathrm{d}$ " hereafter). Moreover, it was tacitly prohibited to "openly comment" against the decisions of superiors (based on d-3). The superiors confessed that they could not determine their employees' thoughts at the time.

First, the results of the data indicated a large power distance of collectivist culture $(d-1,3)$ in the early stage of the company. We assumed that the collectivist culture

\footnotetext{
11 According to Nikkei (December 1, 2017), a famous Japanese dictionary named Basic Knowledge, chose "Sontaku" for the Buzzword Grand Annual Prize because the word is frequently used in association with Moritomo and Kake school problems. Through mass media the word became popular after a political scandal involving
}

constrained the "sensemaking" process by organizational members.

Second, the discourse (d-1) indicated that employees tried to read the superiors' unspoken orders. The term "Sontaku" 11 " expresses tacit understanding and has been taken up in Japanese mass media, which loosely translates to "following unspoken orders." We decided to employ the term and examine the connection within the context of this study. In the Japanese dictionary, the term is defined as: "considering how superiors feel without them mentioning it." The term has been employed as one of the traditional traits of Japanese collectivist culture. However, it may sound strange to the Western culture, that superiors gave no clear orders. We demonstrated the term in the abovementioned framework of Markus and Kitayama [16]. The relationship of "Sontaku" between a member and an executive is shown in Figure 5.

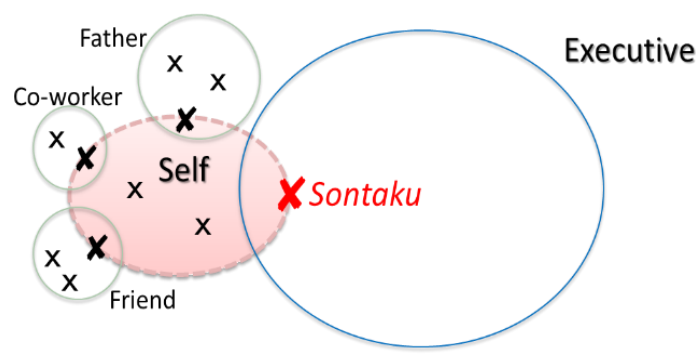

Figure 5. "Sontaku" for the executive

We presume that the member has to react with special tacit understanding to superiors based on the atmosphere created by them in the workplace. Specifically, nonverbal communication is key in such a communication style, not the questionable content, such as manner of speaking or facial expression. The positive aspect of "Sontaku" is to smooth human relationships and work processes in a top-down-structured organization. However, there will inevitably be some problems. We found that "Sontaku" negatively affects individuals and organizations in the large power distance of collectivist culture. First, superiors cannot understand the employees' real expectations (based on d-2) because the members try to hide their thoughts and pretend to have a submissive attitude toward superiors. This means that employees and superiors do not proactively feel responsible for the collective result. Second, it forces the member to repress natural emotions and opinions (based on d-3); thus, members gradually lose their positive attitude toward their work.

Prime Minister Abe Shinzo, who insisted on not testifying to bureaucracy, in which the national bureaucracy considered minister Abe's intention to resolve the scandal. Moreover, mass media reported that a bureaucrat committed suicide because he claimed responsibility for the scandal. 
This study suggests that one of the reasons "in-house communication discord" was a significant barrier to teleworking, derives from the high-context Japanese communication style, which is based on the place's atmosphere created by superiors' nonverbal communication. This can be symbolized with a tacit understanding of "Sontaku." Next, we infer that such a high-context communication style can be performed only via face-to-face interaction and not online using diffused modern technology. Furthermore, we presume that this finding is also the reason why many Japanese superiors think twice before introducing telework. However, DUNKSOFT positively introduced telework in 2011. How did this affect the company? Next, we investigate RQ2/RQ3.

\subsection{Examination of $R Q 2 / R Q 3$}

Here, we examine discourses 4-22 and discuss the change experienced by the company due to the introduction of telework, considering its organizational identity (Table 5).

According to the above discourses, we can identify two types of organizational traits, indicating differences before and after the landmark phase. Discourses in the former include: "Working until midnight, and the resignation rate was high" (d-4), "Perfectly top-down management" (d-6), and "Obliged to work by superiors" (d-7). Discourses in the latter phase include: "A 'polyvalent' role by having autonomous motivation" (d8), "Assertion can be true" (d-11), "A slogan "you said it first", (d-12), "Talked to each other on a private level as if in a family" (d-13), "Rules of maternity leave for three years" (d-14), "Work freely everywhere" (d-19), and "Self-sacrifice for the company is bad" (d-20).

In other words, the company changed from using the top-down to the bottom-up decision-making process (based on d-6 and d-11). Since then, the employees' attitudes changed from passive action and low commitment to autonomous and ideal actions (based on d-7 and d-8). Additionally, the company transformed, from having to work long hours and being obligated to work by superiors, to encouraging a work-life balance and allowing employees to work freely from anywhere, through telework (d-4, d-14, and d-20).

Here, we compare the new organizational beliefs with those of a family (d-13) and that which opposes self-sacrifice for the company's good (d-20). Because company's central characters share those beliefs, we, therefore, clarify that: 1) the company had changed in the landmark era; and 2) the change was accompanied by a transformation in the organizational identity (above all, central character). What was the trigger of this change? Additionally, what kind of symbols did this affect?
Table 5. Discourses regarding $R Q 2 / R Q 3$

RQ2: Change of the organization through the introduction of telework

RQ3: Emergence of a new organizational identity

4) Working until midnight, and the resignation rate was high (Mr. K. H.)

5) Afraid that they will leave our company if I could not provide good working conditions (Mr. K. H.)

6) Perfectly top-down management (Ms. K. N.)

7) Obliged to work by superiors (Ms. K. N.)

8) A "polyvalent" role by having autonomous motivation (Mr. K. H.)

9) Empowered the recruitment department to ensure the appointment of talented newcomers (Mr. K. H.)

10) Way the superiors dealt with us had gradually changed (Ms. K. N.)

11) Assertion can be true (Ms. K. N.)

12) A slogan "you said it first" (Mr. K. H.)

13) Talked informally to each other (Ms. K. N.)

14) Change maternity leave rules to three years (Ms. K. N.)

15) Change of the company's new logo by majority decision (Ms. K. N.)

16) Difficult for a small and insignificant company such as DUNKSOFT to hire talented and skilled workers (Mr. K. H.)

17) Full-scale telework using teleconference system (Mr. K. H.)

18) Got a sense of fulfillment in my work (Mr. Y. T.)

19) Work freely from anywhere (Mr. Y. T.)

20) Self-sacrifice for the company is bad (Mr. Y. T.)

21) Our company is exceptional (Mr. K. H.)

22) New in-house trials developed into a new business (Mr. K. H.)

When reviewing the discourses more carefully, it became clear that it was because the executive was afraid that talented newcomers would leave the company if he could not provide a good work environment (d-5). Therefore, he empowered them (d9) with the slogan "you said it first." (d-12). Simultaneously, he began to make an effort to listen to their needs (d-10). As the slogan inspired employees' actions, it had special meaning as verbal symbols and a leader's symbolic action. The symbol meant sensegiving. The other symbolic actions were, for example, a member proposing rules of maternity leave for three years (d-14), which was accepted. Further, an important and symbolic event was the decision to change the company's logo, approved by the majority (d-15) (see Figure 6).

The left picture shows the executive's old logo, and the right indicates the new logo developed by the design staff. The right-hand logo materialized as a symbol resulting from sensemaking. As a result, the large power distance in collectivist culture was gradually amended to its counterpart, thus promoting the sensegiving 
process, which became the basis for the emergence of new shared identity in the company.

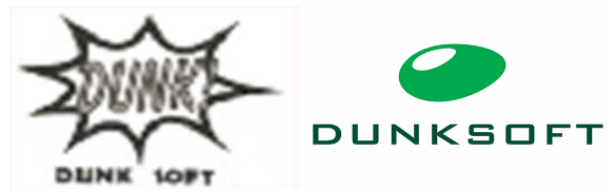

Source: the pictures were provided by DUNKSOFT.

\section{Figure 6. Change of company's logo}

Further, as the executive realized the difficulty of hiring talented and skilled workers in Tokyo, he introduced full-scale telework and a teleconference system (d-17) such that suburban employees could work continuously. We presume that a leader proposed the ICT infrastructures as a result of sensegiving through material symbols. The executive established a satellite office for meeting the needs of regional applicants. Subsequently, the company was awarded 14 prizes, for instance encouraging a work-life balance. At the same time, superiors and employees were reminded that the company is exceptional (d-21), which indicates the rise of distinction and uniqueness in shared identity. Finally, we suggest that the whole correspondence between discourses, symbols, and the concepts of sensegiving and sensemaking occurred in the landmark change of the company (Figure 7).

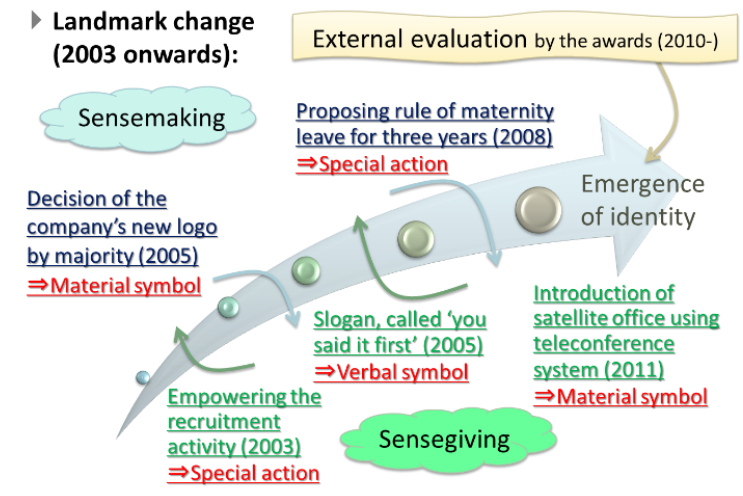

Figure 7. Emerging process of new identity

For example, the in-house trials, the introduction of full-scale telework resulted in the development of new businesses as a consulting service of the regional revival by telework (based on d-22). We emphasize that telework introduction became a means of organizational identity change and new competence acquisition in the company.

\section{Conclusions}

This study investigated three research questions through the qualitative analysis: "How does an organizational member organize themself through others in a high-context culture, by face-to-face interaction?" (RQ1); and "Is there any change in the organization through the introduction of telework?", "Is there an emergence of a new organizational identity?" (RQ2/RQ3). In the former, we suggest that one reason why "in-house communication discord" was the significant barrier to adopting teleworking practices, derives from the high-context Japanese communication style. We concluded that this could be symbolized in the tacit understanding of "Sontaku," which is mainly based on a large power distance. Regarding the second and third questions, the study confirmed organizational change due to transforming an organization's "central character." Our study emphasized that if a non-Western cultural company introduces telework, it should remove the negative aspects of the communication style associated with collectivist culture to bring about organizational change that leads to a new organizational identity. Additionally, as Ravasi and Schultz [27] noted, we point out that sharing new aspects of organizational identity through members and the executive was complemented by the external evaluation, which promotes an organization's "distinctiveness." In the three symbols mentioned above, we suggest that material symbols played a significant role in sensegiving and sensemaking for organizational identity change, which is concluded in discourses regarding the company's logo and the ICT infrastructures. Finally, this study emphasizes that superiors and members selfreflectively perceived their uniqueness and that the identity changed regardless of that perception.

However, there remain some issues in this study. First, we have not yet interviewed all members of the company. Interviewing everyone to hear their stories will reveal further insights. Second, surveying the number of companies, even including pre-interviewed companies, is insufficient to draw reliable conclusions. Third, since our main focus was on the concepts of "central character" and "distinctiveness" among the three dimensions of organizational identity, the remaining dimension of "temporal continuity" should be further examined in a subsequent study. We will conduct further research and examine the findings of this study.

\section{References}

[1] L. Huff, and L. Kelley, "Levels of organizational trust in individualist versus collectivist societies: A seven-nation study," Organization Science, The Institute for Operations Research and the Management Sciences, MD, 14 (1), 2003, pp. 81-90. https://doi.org/10.1287/orsc. 14. 1. 81.12807

[2] G. Sewell, and L. Taskin, "Out of sight, out of mind in a new world of work: Autonomy, control, and 
spatiotemporal scaling in telework," Organization Studies, Sage, CA, 36(11), pp. 1507-1529, 2015. https: // doi. org/10.1177/0170840615593587

[3] J. M. Nilles, F. R. Carlson, Jr. P. Gray, and G. J. Hanneman, The telecommunications-transportation tradeoff: Options for tomorrow, John Wiley \& Sons, NY, 1976.

[4] Onishi, T. Telecommuting changes cities, Nihon Keizai Shimbun, Tokyo, 1992.

[5] Spinks, W. A. Telework century, Japan Institute for Labor Policy and Training, Tokyo, 1998.

[6] S. J. Barnes, "Information management research and practice in the post-COVID-19 world," International Journal of Information Management, Elsevier, Amsterdam, 55, 102175, 2020.

[7] L. D. Parker, "The COVID-19 office in transition: Cost, efficiency and the social responsibility business case," Accounting, Auditing and Accountability Journal, Emerald Publishing, Bingley (UK), 33(8), pp. 19431967, 2020.https://doi.org/10.1108/AAAJ-06-2020-4609

[8] Nomura Institute of Research, "Knowledge Insight Report," Nomura Institute of Research, Tokyo, 20201218.https://www.nri.com/media/Corporate/jp/File s/PDF/knowledge/report/cc/digital_economy/20201218. pdf, 2020. Accessed April 13, 2021.

[9] A. Kimata, "A Study of the Impediments to Japanese Telework," International Journal of Japan Association for Management Systems, Japan Association for Management Systems, Tokyo, 3(1), pp. 15-23, 2011.

[10] G. Hofstede, Culture's Consequences: International Differences in Work-Related Values, Sage, CA, 1984.

[11] G. Hofstede, Cultures and organizations: Software of the mind, McGraw-Hill International, London, 1991.

[12] N. Ramamoorthy, and S. J. Carroll, "Individualism/ collectivism orientations and reactions toward alternative human resource management practices," Human Relations, Sage, CA, 51(5), pp. 571-588, 1998. https://doi.org/10.1177/001872679805100501

[13] T. Yamagishi, Society from "Anshin" to trust (in Japanese), Chuokoron-shinsya, Tokyo, 1999.

[14] T. Yamagishi, The evolutionary game of mind and society, Springer, Berlin, 2011.

[15] P. L. Mokhtarian, and K. Sato, "A comparison of the policy, social, and cultural contexts for telecommuting in Japan and the United States," Social Science Computer Review, Sage, CA, 12(4), pp. 641-658, 1994. https://doi.org/10.1177/089443939401200412

[16] H. R. Markus, and S. Kitayama, "Culture and the self: Implications for cognition, emotion, and motivation," Psychological review, American Psychological Association, WA, 98(2), pp. 224-253, 1991.

[17] E. T. Hall, Beyond culture, Anchor Books/Doubleday, NY, 1976.

[18] B. M. Cole "Lessons from a martial arts dojo: A prolonged process model of high-context communication", Academy of Management Journal, Academy of Management, NY, 58(2), pp. 567-591, 2015.

[19] P. Prasad, "Symbolic processes in the implementation of technological change: A symbolic interactionist study of work computerization," Academy of Management Journal, Academy of Management, NY, 36(6), pp. 14001429, 1993.

[20] L. Smircich, "Concepts of culture and organizational analysis," Administrative Science Quarterly, Sage, CA, 28(3), pp. 339-358, 1983.

[21] T. C. Dandridge, I. Mitroff, and W. F. Joyce, "Organizational symbolism: A topic to expand organizational analysis," Academy of Management Review, Academy of Management, NY, 5(1), pp. 77-82, 1980.

[22] M. J. Hatch, and M. Schultz, "The dynamics of organizational identity," Human Relations, Sage, CA, 55(8), pp. 989-1018, 2002. https://doi.org/10.1177/0018 726702055008181

[23] D. A. Gioia, M. Schultz, and K. G. Corley, "Organizational identity, image, and adaptive instability," Academy of Management Review, Academy of Management, NY, 25(1), pp. 63-81, 2000. https://doi.org/10.5465/amr.2000.2791603

[24] S. M. Clark, D. A. Gioia, D. J., Jr. Ketchen, and J. B. Thomas, "Transitional identity as a facilitator of organizational identity change during a merger," Administrative Science Quarterly, Sage, 55(3), pp. 397438, 2010. https://doi.org/10.2189/asqu.2010.55.3.397

[25] M. Anteby, and V. Molnár, "Collective memory meets organizational identity: Remembering to forget in a firm's rhetorical history," Academy of Management Journal, Academy of Management, NY, 55(3), pp. 515540, 2012. https://doi.org/10.5465/amj.2010.0245

[26] S. Albert, and D. A. Whetten, "Organizational identity," in L. L. Cummings, and B. M. Staw (Eds.), Research in organizational behavior (pp. 263-295), JAI Press, London, 1985.

[27] D. Ravasi, and M. Schultz, "Responding to organizational identity threats: Exploring the role of organizational culture," Academy of Management Journal, Academy of Management, NY, 49(3), pp. 433-458, 2006.

[28] D. Ravasi, and A. Canato, "How do I know who you think you are? A review of research methods on organizational identity," International Journal of Management Reviews, John Wiley \& Sons, NY, 15(2). pp. 185-204, 2013. https://doi.org/10.1111/ijmr.12008

[29] E. H. Erikson, Identity and the life cycle, International Universities Press, NY, 1959.

[30] C. G. Jung, Memories, dreams, reflections, recorded and edited by Aniela Jaffé, translated from the German by Richard and Clara Winston, Collins and Routledge \& Kegan Paul, London, 1963.

[31] R. K. Yin, Case study research 2/e, Sage Publications, CA, 1994.

[32] V. Burr, An introduction to social constructionism, Routledge, London, 1995.

The work supported by Japan Society for the Promotion of Science (JSPS) KAKENHI Grant Number 20K01934. The authors wish to thank the referees for useful comments. 